\title{
EL carácter biplánico del investigador científico: investigar y publicar
}

\author{
The two-stage character of the researcher: \\ investigate and publish
}

\author{
Eduardo Cajandilay-Díaz 1,a, Manuel R. Trifúl-Ortíz 1,b, Heber Silva-Díaz 3,c
}

Los aprendices calcan y luego copian; con el tiempo, se integran a un proceso de producción estandarizado. Finalmente, si tienen capacidad, pueden crear su propia versión, salirse del molde, acuñar un estilo. Es un proceso ${ }^{(1)}$. Es una actividad compleja que requiere preparación y constancia. Investigar y publicar deberían ser asumidas como competencias transversales en la vida académica y profesional. Sin embargo, nuestra realidad es otra. El Consejo Nacional de Ciencia, Tecnología e Innovación Tecnológica del Perú (Concytec), ha manifestado que existe una brecha de más de 15 mil investigadores con doctorados, en referencia a países similares ${ }^{(2)}$. Esto se ve reflejado en la poca producción científica en nuestro país. Realidad que no guarda relación con la cantidad de posgrados, especializaciones y demás actividades académicas que deberían garantizar la investigación y publicación.

El país, a través del Concytec, está implementando políticas públicas para reducir la falta de investigadores, pero estos investigadores deberán ser no solo de mayor calidad, sino de mayor integridad científica. En este sentido, la formación científica en el Perú requiere de la intervención de la educación básica y universitaria para promover las habilidades investigativas en la niñez, la adolescencia y juventud. Por lo tanto, se requiere inspirar los nuevos talentos desde una nueva óptica de la enseñanza científica, reconociendo a la lectura y la ética como herramientas claves para estos propósitos ${ }^{(3)}$.

El proceso de la investigación científica en la Educación Superior tiene una doble función: contribuye a la formación del profesional y es, además, una vía óptima para resolver problemas complejos que se presentan en la sociedad ${ }^{(4)}$. Es decir, este carácter biplánico del investigador brinda una notable importancia al profesional. Porque le permite solucionar problemas reales y de trascendencia. Lo hace desde sus diversas formas, individual, colectiva o corporativa, en las que brinda pautas comprobadas para su correcta ejecución. Investigar y publicar permiten desplegar las competencias y potencialidades del profesional. Además, con su aporte científico le permitirá estar a la vanguardia en su línea de investigación.

La investigación científica y la publicación del artículo científico son dos actividades íntimamente relacionadas. La investigación termina con la publicación como artículo en una revista científica ${ }^{(5)}$. Ciencia que no se comunica no existe porque, como en muchos campos de la vida social y humana, las cosas solo existen a partir de que existan en el mundo de la comunicación ${ }^{(6)}$. Pueden existir muy buenas investigaciones que enriquezcan el corpus científico, pero si no se hace de conocimiento de la comunidad científica, este aporte no trasciende, no se replica y no aporta a la solución de problemas similares en diversos contextos.

La investigación y la publicación como actividades complejas están supeditadas a dos competencias mayores o también llámese habilidades comunicativas "Leer y escribir". La investigación implica lectura especializada y profunda. La publicación científica supone escritura técnica y objetiva. La escritura y la lectura (tanto o más que lo que decimos, la ropa que usamos o lo que comemos) constituyen nuestra identidad, porque son la imagen que presentamos frente a los demás, es decir, son el rostro que los otros miran ${ }^{(7)}$. Por lo tanto, resulta ineludible desarrollar habilidades de lectura y escritura y con ellas habilidades investigativas desde la educación básica hasta niveles superiores. Estas acciones permitirán generar investigación de calidad y aumentar exponencialmente las publicaciones y con ello la solución de problemas sociales.

\footnotetext{
Universidad Alas Peruanas-filial Jaén, Cajamarca,Perú.

2 Dirección de Investigación, Hospital Regional Lambayeque,Lambayeque, Perú.

a Doctor en Administración de la Educación.

b Doctor en Ciencias de la Educación

Biólogo, doctor en ciencias.
} 
La investigación supone lectura y esta implica la percepción crítica, interpretación y reescritura de lo leído. Un buen investigador tiene que ser un excelente lector, sumergirse en su investigación, apropiarse, consultar diversas fuentes, diversos puntos de vista. La lectura se convierte en una herramienta expresamente relevante. De ahí que, si se quiere realizar una muy buena investigación es implícito que se va a realizar una muy buena lectura. Finalmente, la lectura y con ella la comprensión lectora, son habilidades del investigador, que desde su rol del lector interactúa con el texto en un contexto determinado.

La publicación implica escritura, pero escribir es mucho más que conocer el abecedario asociar letras en palabras y frases coherentes. Escribir es ser capaz de expresar información de forma coherente y correcta para que entiendan otras personas ${ }^{(7)}$. Así, la actividad de publicar requiere destrezas y habilidades de escritura, que se adquieren con la práctica y la constancia. Saber hilvanar las ideas, estructurarlas, comunicar los principales hallazgos de una investigación requiere escribir las ideas. Así, la publicación requiere escribir la investigación, revisarla y compartirla para conocimiento público.

Si investigar y publicar guardan estrecha relación, también parece ser imprescindible que todos los buenos escritores son o han sido durante un largo periodo de su vida, buenos lectores ${ }^{(8)}$. Por lo que estas dos habilidades tienen que ser el soporte para investigar y publicar. Más aún con todo el avance de la tecnología las posibilidades de publicar son mayores, porque incluso el cambio más trascendental que implica internet es que la lectura y la escritura se producen en línea, o sea conectados a millones de recursos, que aprovechamos para construir significados de manera diferente y más sofisticados ${ }^{\left({ }^{9}\right.}$. De tal modo que hay más herramientas disponibles para que las publicaciones estén mejor constituidas y enmarcadas en una clara ética profesional en beneficio de solucionar problemas sociales.

En conclusión, investigar y publicar poseen un carácter biplánico en el investigador, pero estas dos herramientas se nutren con la lectura y escritura. De este modo, se tiene que promover el desarrollo de estas habilidades desde los primeros grados de escolaridad, para que las investigaciones y publicaciones aporten al desarrollo del país. Porque sin estas herramientas muchas investigaciones quedarán en buenas intenciones, no trascienden, no contribuyen con enriquecer el corpus científico y mucho menos se replicarán en la solución de problemas reales.

\section{REFERENCIAS BIBLIOGRÁFICAS}

1. Durand J. El oficio de investigar*. UNAM, Instituto de Investigaciones Sociales. 2012;73:45-73.

2. Concytec. Comisión de Educación aprueba por unanimidad dictamen de Pro-moción del Investigador Científico que impulsa el Concytec [Internet]. Con-cytec. 2018 [cited 2018 Apr 28].Available from: https://portal.concytec. gob.pe/index.php/noticias/1263-comision-de-educacion-aprueba-por-unanimidad-dic-tamen-de-promocion-del-investigador-cientifico-que-impulsa-el-concytec
3. Silva-Díaz, H., Cajandilay-Díaz, E. Formación científica en el Perú: actualidad y retos. Rev Exp Med. 2018; 4(3): 117 - 118.

4. Alvares CM, Sierra VM. Solución de problemas profesionales. Metodología de la investigación científica. Cochabamba: Grupo editorial Kipus. 2009; 234 p.

5. Grandi, C., Der Parsehian S. La importancia de investigar y publicar: 30 a ños de revista Sardá. Rev. Hosp. Mat. Inf. Ramón Sardá. 2011;30(1):2-3.

6. Rojas R. ¿Por qué publicar artículos científicos ?. Revista Científica Electrónica de Ciencias Humanas. 2008;10(4):120-137.

7. Albarrán C. Cómo escriben los que escriben. Fondo de cutlura económica, Ins tituto Tecnológico de México. México, D.F. 2011: 112p.

8. Cassany D. Describir el escribir. Cómo se aprende a escribir. Comunicación Paidos, editor. Barcelona, España. 2015: 232p.

9. Cassany D. En_línea. Anagrama, editor. Barcelona, España. 2012: 282p. 